ydryl group of the apo-protein as reported in the previous communication ${ }^{6}$, the results obtained here suggest that benzoate does not combine with adenylic acid part of flavin adenine dinucleotide.

From these results, it may be concluded that the isoalloxazine nucleus of flavin adenine dinucleotide binds with both the apo-protein and the substrate by its two different binding sites, and that the binding site in adenylic acid part of flavin adenine dinucleotide joins only with the binding site of the apo-protein.

KUNIO YAGI TAKaYUKI Ozawa

Department of Biochemistry,

MrNoRU HaRAda

School of Medicine,

Nagoya University,

Nagoya, Japan.

Aug. 17.

1 Negelein, E., and Brömel, H., Biochem. Z., 300, 225 (1939).

2 Yagi, K., Matsuoka, Y., Kuyama, S., and Tada, M., J. Biochem., 43, 93 (1956).

${ }^{3}$ Kuło, H., Symp, on Enzyme Chem. (Japan), 5, 1 (1950).

4 Klein, J. R., J. Biol. Chem., 205, 725 (1953)

5 Yagi, K., Ozawa, T., and Okada, K., Biochim. Biophys. Acta (in the

Yagi, K., and Ozawa, T., Nature (in the press).

\section{Occurrence of Polynucleotide Phosphorylase in Atypical Epithelioma of Rat}

SINCE the discovery of polynucleotide phosphorylase in Azotobacter vinelandi ${ }^{1,2,3}$, its wide distribution has been expected concerning its actual meaning in polynucleotide synthesis in living body. Though it has been found to exist in several bacteria 4,5 , its occurrence in animal source has not been demon. strated except in human sperm reported by Hakim ${ }^{6}$. In our laboratory, the existence of this enzyme in animal cells has been examined, and the occurrence of it in atypical epithelioma (Guerin strain) was found. The results are briefly reported here.

The tissue of atypical epithelioma of a rat about two weeks after transplantation was removed immediately after decapitation of the animal and was immersed at once in ice-cold 0.9 per cent sodium chloride solution. The supporting connective tissue and areas of necrosis of this epithelioma tissue were carefully removed. Then the tissue was homogenized with four times of its volume of $0.05 M$ tris(hydroxymethyl)aminomethane buffer, $p \mathrm{H} \quad 7.4$ at about $0^{\circ}$. The isolation and partial purification of polynucleotide phosphorylase was carried out with this extract of atypical epithelioma according to the method of Littauer and Kornberg ${ }^{5}$ : namely, manganese chloride was added to the extract, and the enzyme in the supernatant obtained by the centrifugation of this mixture was adsorbed on protamine sulphate and was eluted. The nucleic acid content of this enzyme preparation was calculated to be 1.5 per cent of protein concentration, from the ratio of optical density at $280 \mathrm{~m} \mu$ to that of $260 \mathrm{~m} \mu$. Then the preparation was further purified by zinc-ethanol fractionation. The preparation obtained by this fractionation was used for enzymic reactions.

The measurements of activity of this enzyme were carried out according to the method of Beers ${ }^{4}$. The enzymic reaction mixtures were composed of each $0.5 \mathrm{ml}$. of enzyme preparation, $2 \mathrm{~m}$. moles of adenosine$5^{\prime}$-diphosphate, 3 m.moles of magnesium chloride and $0.1 M$ tris(hydroxymethyl)aminomethane buffer, $p \mathrm{H} 10^{\circ} 0$. The solution was incubated at $37^{\circ}$ for $15 \mathrm{~min}$. Then $2 \mathrm{ml}$. of 5 per cent $(\mathrm{w} / \mathrm{v})$ perchloric acid was added to the reaction mixture and precipitate formed was collected by centrifugation. As controls, the

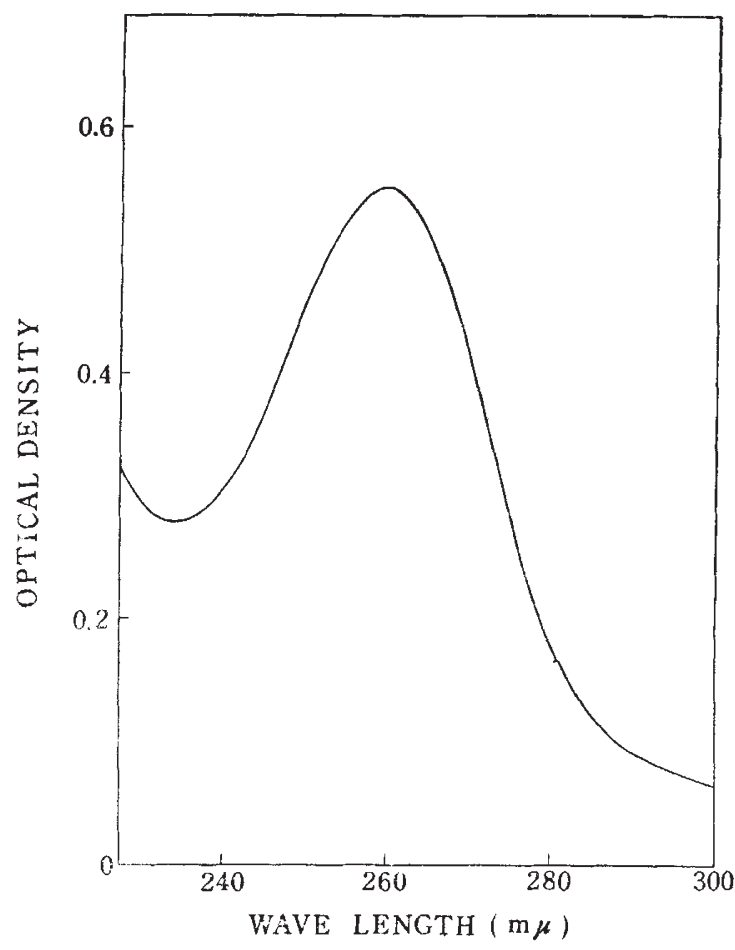

Fig. 1. Absorption spectrum of synthesized adenosine-5r phosphate polymer catalysed by polynucleotide phosphorylase extracted from atypical epithelioma of rat. The lllustrated spectrum is that of the reaction product of polynucleotide phosphorylase at $37^{\circ}$ for 15 min

following two experiments were performed: (1) the same reaction mixture as above was added with perchloric acid without incubation; (2) the reaction mixture without adenosine $-5^{\prime}$-diphosphate was treated in the same way as the main experiment. The precipitate was washed by 5 per cent perchloric acid (w/v) and then washed twice by 95 per cent ethanol. Finally the sediment was suspended in $0.1 M$ tris(hydroxymethyl)aminomethane buffer, $p \mathrm{H} \quad 8 \cdot 0$. The insoluble denatured enzyme protein was centrifuged off. The absorption spectrum of the supernatant thus obtained which is considered to contain only adenosine $-5^{\prime}$-phosphate polymer is shown in Fig. 1 . The maximum absorption of this synthesized polymer exists at $260 \mathrm{~m} \mu$. The optical densities at $260 \mathrm{~m} \mu$ measured with the main experiments were found to be $0 \cdot 5-0 \cdot 7$, whereas those of the controls were less than 0.05 .

The synthetic activity of polynucleotide phosphorylase found in an epithelioma is of special interest from the point of view of rapid growth of neoplasmatic tissue.

KUNIO YAGI

TakaYuki Ozawa

Hiroshi Konogi

Department of Biochemistry,

School of Medicine,

Nagoya University,

Nagoya, Japan.

Aug, 1.

${ }^{1}$ Grunberg-Manago, M., and Ochoa, S., J. Amer. Chem. Soc., 77, 3165 (1955)

Grunberg-Manago, M., Ortiz, Y. J., and Ochoa, S., Science, 122, 907 $(1955)$.

Grunberg-Manago, M., Ortiz, P. J.s and Ochoa, S., Biochim. Biophys. Acta, 20, 269 (1956).

4 Becrs, R. F., jun., Biochem. J., 66, 687 (1957).

s Littauer, U.' Z., and Kornberg, A., J. Biol. Chem., 226, 1077 (1957).
- Hakim, A. A., Nature, 183, 335 (i959). 